\title{
Brace treatment for patients with scoliosis: State of the art
}

\begin{tabular}{|c|c|}
\hline \multicolumn{2}{|c|}{$\begin{array}{l}\text { Authors: } \\
\text { Hans-Rudolf Weiss }{ }^{1} \text { (D) } \\
\text { Tuğba Kuru Çolak }{ }^{2} \text { (D) } \\
\text { Manuel Lay }{ }^{3} \text { (D) } \\
\text { Maksym Borysov }^{4} \text { (D) }\end{array}$} \\
\hline \multicolumn{2}{|c|}{$\begin{array}{l}\text { Affiliations: } \\
{ }^{1} \text { Institution of Schroth } \\
\text { Best Practice Academy, } \\
\text { Neu-Bamberg, Germany }\end{array}$} \\
\hline $\begin{array}{l}{ }^{2} \text { Physiotherap } \\
\text { Rehabilitation } \\
\text { Faculty of Hea } \\
\text { Marmara Univ } \\
\text { Istanbul, Turk }\end{array}$ & $\begin{array}{l}\text { and } \\
\text { Department, } \\
\text { Ith Sciences, } \\
\text { ersity, } \\
y\end{array}$ \\
\hline \multicolumn{2}{|c|}{$\begin{array}{l}{ }^{3} \text { Institution of Orthopädie- } \\
\text { Technik Lay GmbH, Zell-Barl, } \\
\text { Mosel, Germany }\end{array}$} \\
\hline \multicolumn{2}{|c|}{$\begin{array}{l}{ }^{4} \text { Institution of Orttech-plus } \\
\text { Rehabilitation Service, } \\
\text { Charkiv, Ukraine }\end{array}$} \\
\hline \multicolumn{2}{|c|}{$\begin{array}{l}\text { Corresponding author: } \\
\text { Hans-Rudolf Weiss, } \\
\text { hr.weiss@koob-skoliose.com }\end{array}$} \\
\hline \multicolumn{2}{|c|}{$\begin{array}{l}\text { Received: } 15 \text { Mar. } 2021 \\
\text { Accepted: } 29 \text { July } 2021 \\
\text { Published: } 26 \text { Oct. } 2021\end{array}$} \\
\hline \multicolumn{2}{|c|}{$\begin{array}{l}\text { How to cite this article: } \\
\text { Weiss, H-R., Kuru Çolak, T., } \\
\text { Lay, M. \& Borysov, M., 2021, } \\
\text { 'Brace treatment for patients } \\
\text { with scoliosis: State of the } \\
\text { art', South African Journal of } \\
\text { Physiotherapy } 77(2) \text {, a1573. } \\
\text { https://doi.org/10.4102/sajp. } \\
\text { v77i2.1573 }\end{array}$} \\
\hline \multicolumn{2}{|c|}{$\begin{array}{l}\text { Copyright: } \\
\text { (C) 2021. The Authors } \\
\text { Licensee: AOSIS. This } \\
\text { is licensed under the } \\
\text { Creative Commons } \\
\text { Attribution License. }\end{array}$} \\
\hline \multicolumn{2}{|c|}{ Read online: } \\
\hline 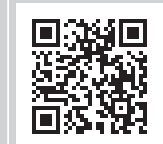 & $\begin{array}{l}\text { Scan this } Q R \\
\text { code with your } \\
\text { smart phone or } \\
\text { mobile device } \\
\text { to read online. }\end{array}$ \\
\hline
\end{tabular}

Background: Physiotherapy, brace applications or surgery are the treatment options utilised to manage patients with scoliosis. Many different brace applications are used, and the success rates of orthoses vary.

Objectives: Brace applications can have detrimental impacts on the patient leading to physical discomfort, psychological discomfort, and in some instance the use of braces may even be painful. Therefore, future developments in this field should be aimed at improving the success rate and reducing physical distress experienced by the patient while using brace applications. The purpose of this article is to provide recommendations with respect to the most appropriate bracing approach in general.

Method: A narrative review of the scientific literature was carried out to substantiate the statements made in this article.

Results: The most important braces provided for the treatment of patients with scoliosis and the treatment results that can be achieved are presented and discussed, taking into account the most recent systematic reviews. A wide range of success rates have been found for the different brace applications.

Conclusion: Given that brace application may impact the patient leading to physical discomfort and psychological distress, good quality management in brace application for patients with scoliosis is needed to ensure the best possible outcome and the least stressful management.

Clinical implications: Safety in brace application for patients with scoliosis needs improvement. The use of standardised and reliable computer aided design (CAD) libraries and appropriate patient information based on published guidelines is suggested.

Keywords: scoliosis; brace application; outcomes; rate of success; cosmesis.

\section{Introduction}

Scoliosis is a three-dimensional deformity of the trunk and spine, which in phases of enhanced growth may deteriorate dramatically (Asher \& Burton 2006; Goldberg et al. 2002; Kruzel \& Moramarco 2020; Landauer, Wimmer \& Behensky 2003). There are numerous causes for scoliotic deformities (e.g. congenital scoliosis with malformations of vertebral bodies and/or ribs, neuromuscular scoliosis, scoliosis in mesenchymal disorders, and many other underlying diseases or syndromes) (Chik 2020). About $80 \%-90 \%$ of all scoliosis cases, however, are of unknown origin and are labelled as idiopathic scoliosis (Asher \& Burton 2006).

Adolescent Idiopathic Scoliosis (AIS) or late onset idiopathic scoliosis is the most prevalent type of scoliosis which most commonly presents in adolescent girls (Asher \& Burton 2006; Kruzel \& Moramarco 2020; Landauer et al. 2003).

Adolescent Idiopathic Scoliosis appears during the pubertal growth spurt and affects girls considerably more (female to male ratio approximately $4: 1$ ) than boys. For curves with angles exceeding $40^{\circ}$, the female to male gender ratio is approximately 10:1 (Asher \& Burton 2006). Treatment of AIS consists of: (1) physiotherapy, (2) brace application, and (3) spinal surgery (Kruzel \& Moramarco 2020).

The first version of the guidelines for conservative scoliosis management were published in 2006 (Weiss et al. 2006) and have been updated recently (Weiss \& Turnbull 2020a). During the pubertal growth spurt, the probability of progression can be calculated for each individual case (Lonstein \& Carlson 1984). A probability for progression of less than $40 \%$ is within the observation range, while the probability for progression of $40 \%-60 \%$ is an indication for 
physiotherapy management, and a probability for progression of $60 \%$ or more is considered as a bracing application indication (Weiss \& Turnbull 2020a).

Brace application in children and adolescents with scoliosis can currently be considered as evidence-based (Weinstein et al. 2013), however, a multitude of different treatment approaches and treatment philosophies exist as outlined below. The most important brace types in use today internationally are the Boston brace and the Chêneau brace. Besides these two main types of braces, night-time braces and soft braces are also available internationally.

\section{The Boston brace}

The Boston brace (Watts, Hall \& Stanish 1977) is a thoracolumbo-sacral orthosis (TLSO) with dorsal closures usually made of polypropylene (PP) with the inside covered with a polyethylene (PE) foam material for better wearing comfort. The Boston brace may be manufactured individually by use of the plaster cast technique. However, prefabricated Boston brace modules are also available as provided by the Boston Orthotics \& Prosthetics located in Avon, MA 02322, USA (Figure 1).

The Boston brace is a symmetric brace usually equipped with pressure pads providing a three-point pressure system aiming to correct the trunk deformity and the spinal curvature. During the pubertal growth spurt, patients are advised to wear the brace for 18-23 hours per day. The flatback deformity usually evident in patients with an idiopathic scoliosis will not be addressed by the application of a typical Boston brace, whilst the lumbar lordosis is usually reduced (Weiss \& Turnbull 2020b).

The Boston brace application is supported by a prospective controlled multi-centre study (Nachemson \& Peterson 1995), and by a randomised controlled study including an untreated control group (Weinstein et al. 2013). Success rates in both these studies are comparable with $70 \%$ and $72 \%$ of patients without recorded curve progression (see Table 1).

\section{The Chêneau brace}

The first Chêneau braces were produced by Dr Chêneau in 1976 (Weiss, Rigo \& Chêneau 2000), and the first end-results were published by Hopf and Heine (1985). The Chêneau brace is an asymmetric brace addressing different curve patterns individually by inducing a corrective movement.

Originally, the Chêneau brace was made via the plaster cast method. A mould is generated for the patient and filled with plaster in order to develop a plaster model of the uncorrected patient. This plaster model is then modified by cutting off plaster from the prominent regions of the trunk and adding plaster opposite to these regions in order to gain space for the desired corrective movement. The final model is then wrapped by a heated high-density PE sheet which is vacuumed to the model's surface.

Compression of the patient's trunk can be avoided when voids opposite to the pressure areas are provided
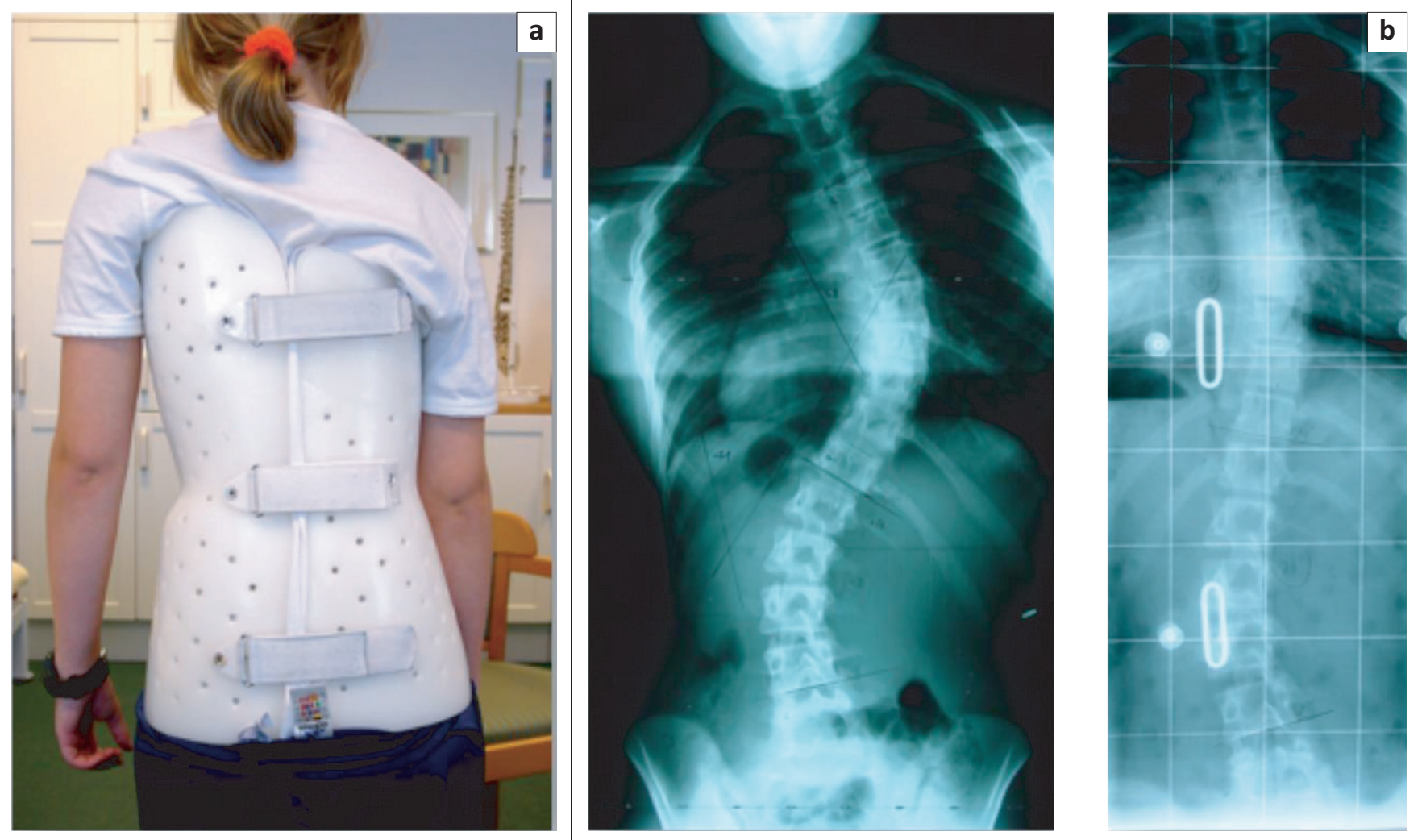

Source: Photos provided by the first author, Hans-Rudolf Weiss

FIGURE 1: (a) Cast made Boston brace, (b) with a very good in-brace correction in an immature patient. 
TABLE 1: Rate of success variations as found in literature for brace treatment for patients with idiopathic scoliosis.

\begin{tabular}{|c|c|c|c|c|c|}
\hline Authors & Year & ROS (\%) & TIB & BT & Comments \\
\hline Nachemson and Peterson & 1995 & 70.00 & Fulltime & Boston & - \\
\hline Hanks, Zimmer and Nogi & 1988 & 81.00 & Fulltime & Wilmington TLSO & More mature sample \\
\hline Weinstein et al. & 2013 & 72.00 & Fulltime & Boston & Success definition: $<50^{\circ}$ \\
\hline Moreau et al. & 2014 & 67.00 & Fulltime & TLSO & Early onset scoliosis \\
\hline Kuroki et al. & 2015 & 67.70 & Fulltime & OMC brace & - \\
\hline Yamane et al. & 2016 & $23.00-58.00$ & Fulltime & TLSO & No outcome study \\
\hline Thompson et al. & 2017 & 65.00 & Fulltime & TLSO & No outcome study \\
\hline Xu et al. & 2017 & 75.00 & Fulltime & TLSO & - \\
\hline Minsk et al. & 2017 & 62.00 & Fulltime & TLSO & Success definition: $<45^{\circ}$ \\
\hline Harshavardhana and Lonstein & 2018 & 41.00 & Fulltime & Boston & Early onset scoliosis \\
\hline Babaee et al. & 2020 & 64.00 & Fulltime & Not specified & Early onset scoliosis \\
\hline Cheung et al. & 2020 & 60.00 & Fulltime & TLSO & - \\
\hline De Mauroy et al. & 2014 & 95.00 & Fulltime & Art brace & - \\
\hline Bullmann et al. & 2004 & 58.00 & Fulltime & Chêneau & - \\
\hline Pham et al. & 2007 & 85.70 & Fulltime & Chêneau & - \\
\hline Zaborowska-Sapeta et al. & 2011 & 48.10 & Fulltime & Chêneau & - \\
\hline De Giorgi et al. & 2013 & 100.00 & Fulltime & Chêneau & Small curves only \\
\hline Minsk et al. & 2017 & 85.00 & Fulltime & Chêneau & Success definition: $<45^{\circ}$ \\
\hline Weiss et al. & 2017 & 92.00 & Fulltime & Chêneau & Curves $>40^{\circ}$ \\
\hline Weiss et al. & 2019 & 92.90 & Fulltime & Chêneau & Success definition: $<50^{\circ}$ \\
\hline Weiss et al. & 2021 & 88.00 & Fulltime & Chêneau & Curves of $25-40^{\circ}$ \\
\hline Weiss et al. & 2021 & 88.00 & Fulltime & Chêneau & Curves of $40^{\circ}$ and more \\
\hline Weiss et al. & 2021 & 96.00 & Fulltime & Chêneau & Success definition: $<50^{\circ}$ \\
\hline D'Amato et al. & 2001 & 74.00 & Nighttime & Charleston & - \\
\hline Seifert and Selle & 2009 & 82.20 & Nighttime & Chêneau & $20-25^{\circ}$ \\
\hline Lee et al. & 2012 & 77.90 & Nighttime & Charleston & - \\
\hline Davis et al. & 2019 & 57.00 & Nighttime & Providence & - \\
\hline Simony et al. & 2019 & 89.00 & Nighttime & Providence & Selected cohort \\
\hline
\end{tabular}

Note: The publications are listed in the order of brace type (Boston or TLSO, Art brace, Chêneau style brace and nightime braces) and by date of publication. Definition of Fulltime may vary (18-23 hours per day); Nighttime is usually defined as 8 hours per night.

ROS, Rate of Sucess; TIB, Time in brace; BT, Brace type.

appropriately. During the pubertal growth, spurt a brace wearing time of $>20$ hours per day is suggested (Asher \& Burton 2006; Kruzel \& Moramarco 2020).

Today, Chêneau applications are designed with a computer aided design (CAD (Figures 2 and 3). These braces may be derived from a brace library based on a curvature pattern classification and are virtually adjusted to the patient's scan on a computer. The file can be used to produce a brace model with a carver, or the brace can be printed (Weiss et al. 2017a).

Chêneau CAD brace series as provided by followers of Dr. Chêneau include the Regnier Chêneau brace (Regnier Orthopaedie $\mathrm{GmbH}$, Achern, Germany), the Rigo System Chêneau or RSC-brace (Ortholutions GmbH \& Co. KG, Rosenheim, Germany) and the Gensingen brace (Koob Scolitech GmbH, Neu-Bamberg, Germany, [Weiss 2010]). Other secondary versions exist but may not be standardised. The term 'Rigo Chêneau' brace is used by numerous technicians who have followed a course by Dr. Rigo, however these braces in the authors' experience may vary to a great extent.

\section{Night-time bracing}

The idea that a corrective brace only has to be worn during the night is certainly appealing for those individuals who have to wear a brace. Therefore, an attempt was made to pre-produce corrective braces for night-time use only. Both the Charleston bending brace (Price et al. 1990) as well as the Providence brace (D'Amato, Griggs \& McCoy 2001) initially provided promising results specifically for night-time use only. Night-time braces are usually worn for $8 \mathrm{~h}$ overnight (Davis et al. 2019; Simony et al. 2019).

Night-time braces are produced by CAD according to hand measurements with the help of measuring tapes and measuring calipers provided by an orthopaedic technician and are sold worldwide (Charleston Brace Company, LLC, Charleston, SC, USA or the Providence Brace by Spinal Technology, Inc., West Yarmouth, MA, USA; Figure 4).

Recent publications have shown contradictory results (Davis et al. 2019; Simony et al. 2019). Therefore, Ruffilli et al. (2021) in their review have stated that a final conclusion about night-time braces cannot be drawn.

\section{Soft braces}

The aim of the application of soft braces has been to increase wearing comfort. There is a lengthy history regarding soft bracing, and the applications as available today may be seen 

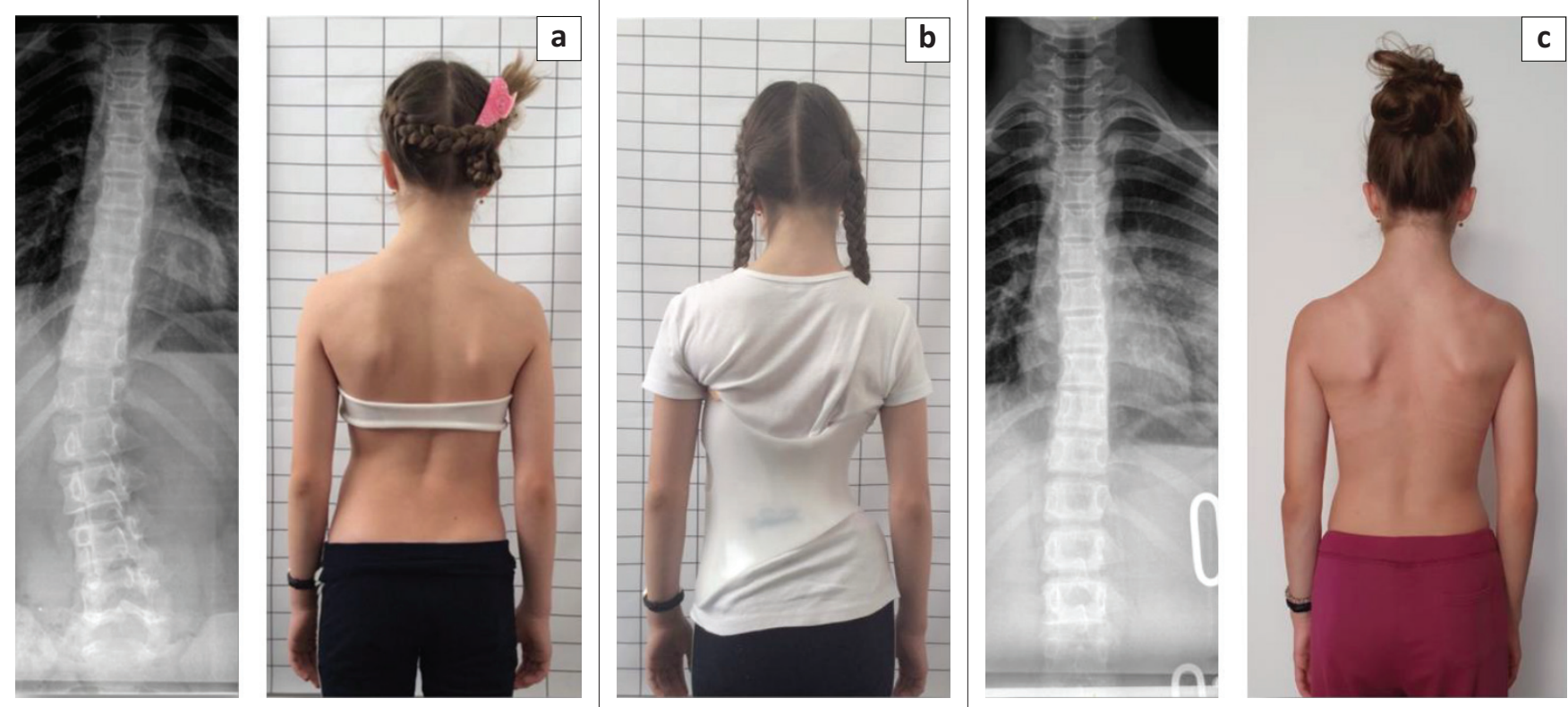

Source: Photos provided by the fourth author, Maksym Borysov

FIGURE 2: (a) Immature patient with a thoracolumbar curve pattern without the brace, (b) with a good in-brace correction in a Chêneau style brace and (c) a good clinical appearance after 9 months of treatment.
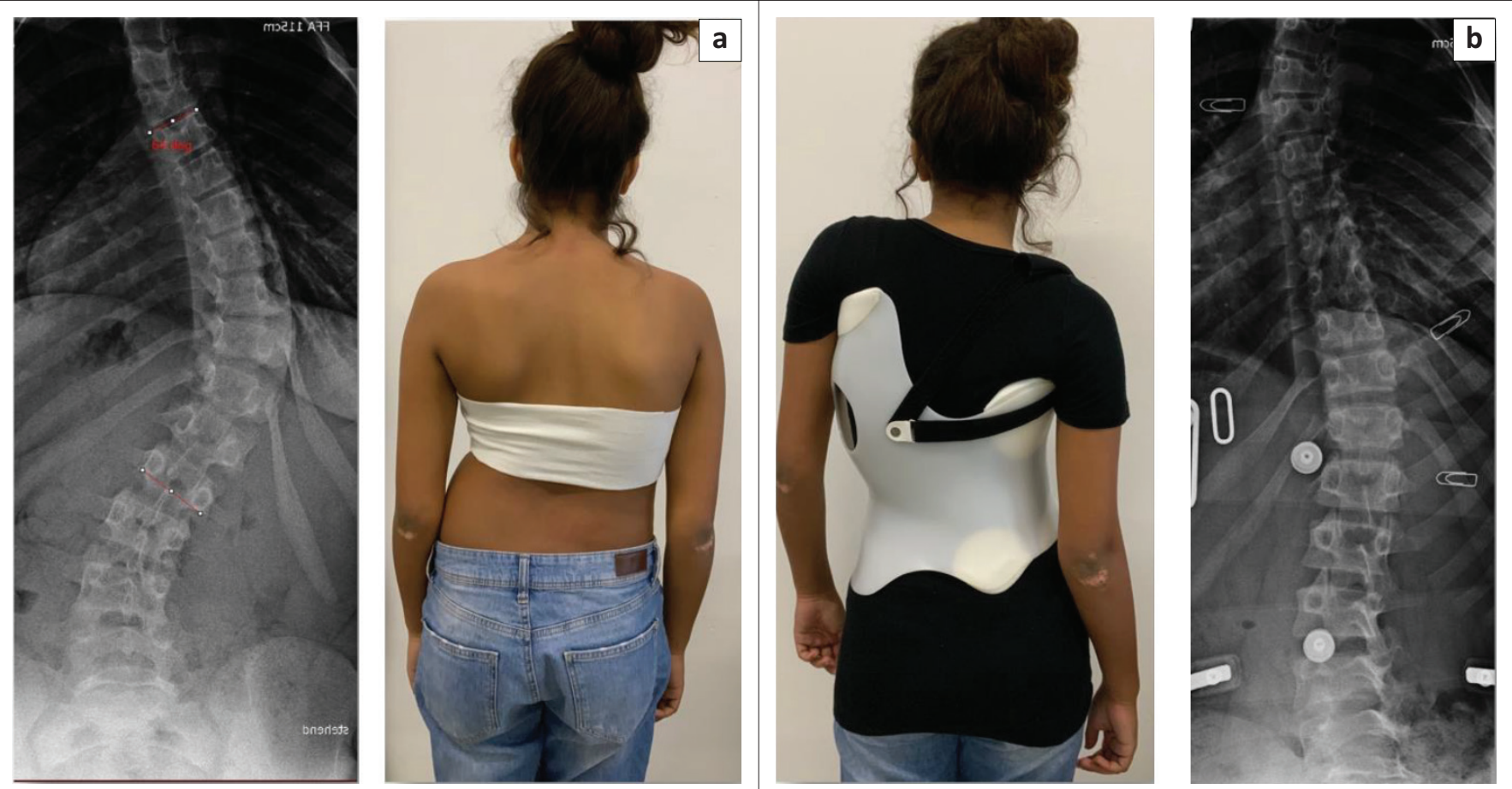

Source: Photos provided by the third author, Manuel Lay

FIGURE 3: (a) Patient with a severe curve exceeding $60^{\circ}$ Cobb angle without the brace and (b) in the special high correction Chêneau style brace (Gensingen brace) for curves exceeding $60^{\circ}$.

as a revival of soft bracing concepts rather than as recent developments (Weiss 2021).

The SpineCor brace (provided by Spine Corporation Limited, Chesterfield, UK), an application with elastic bands, is widespread and advertises free mobility for the individual in the brace (Coillard, Circo \& Rivard 2014). The authors indicated that to initiate and maintain a corrective movement with the SpineCor brace, the brace should be worn full-time during the growing period (Coillard et al. 2014).

The TriaC corset (provided by SPORLASTIC GMBH, Nürtingen, Germany) worn full-time works via a 3-point pressure system (Bulthuis, Veldhuizen \& Nijenbanning 2008) and is not suitable for all curvature patterns. While still in distribution, its use is not widespread. Soft braces are naturally not suitable for the treatment of stiff spinal 


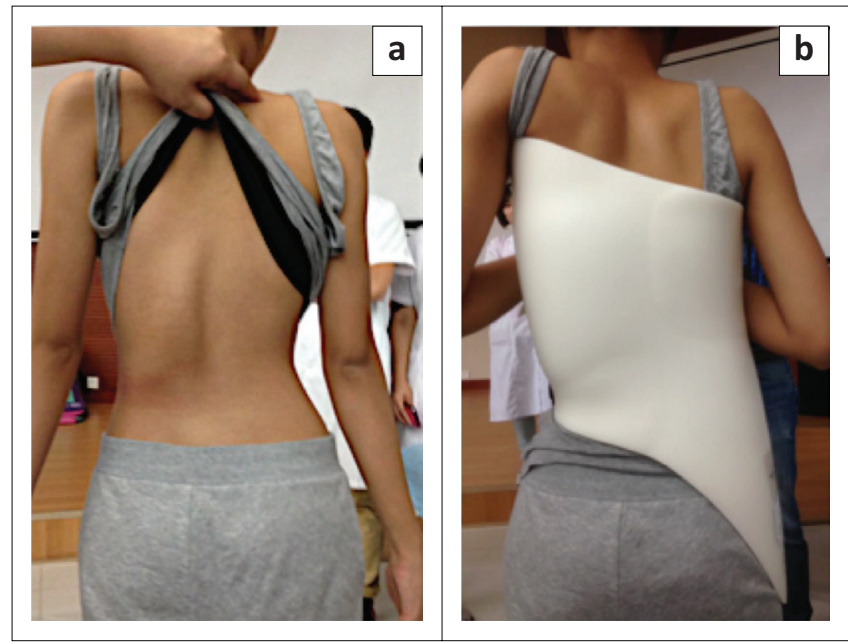

Source: Photos provided by the first author, Hans-Rudolf Weiss

FIGURE 4: (a) Patient with a thoracolumbar curve, (b) treated with a Providence brace.

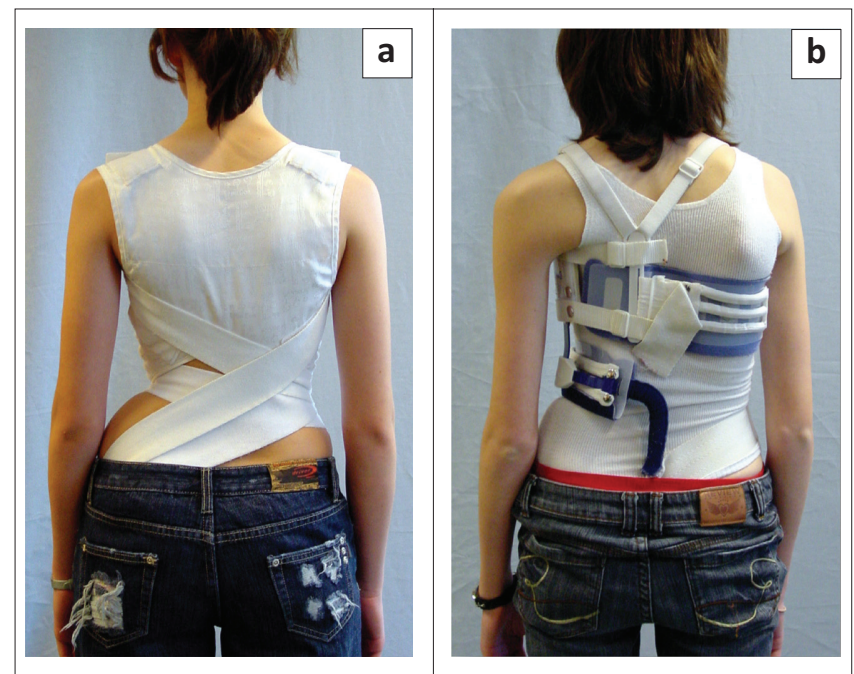

Source: Photos provided by the first author, Hans-Rudolf Weiss

FIGURE 5: (a) Soft braces as available today. SpineCor for a right thoracolumbar curve and (b) TriaC brace for a right thoracic curve. Clinically no real corrective effect is visible.

curvatures, as they do not have the restoring force necessary for a sufficient correction (Weiss \& Weiss 2005; Figure 5).

There are numerous other brace models, the majority of which are regional variations of existing concepts. From a historical point of view, the formerly widespread Milwaukee brace (Blount 1965) must be highlighted, as well as the Lyon brace (De Mauroy, Lecante \& Barral 2011), which still has widespread use in France, but its use is also found occasionally outside of Europe (Figure 6). The further development of the Lyon brace by De Mauroy et al. (2014) has led to a significant improvement in the correction effect and end results. This brace is also currently known as the ART brace (De Mauroy et al. 2014). The Wilmington brace (Hanks, Zimmer \& Nogi 1988) also needs to be mentioned. This TLSO is mainly provided in the United States of America.

Regional symmetrical braces, similar to the Boston brace, correct the curve by compressing the trunk and using

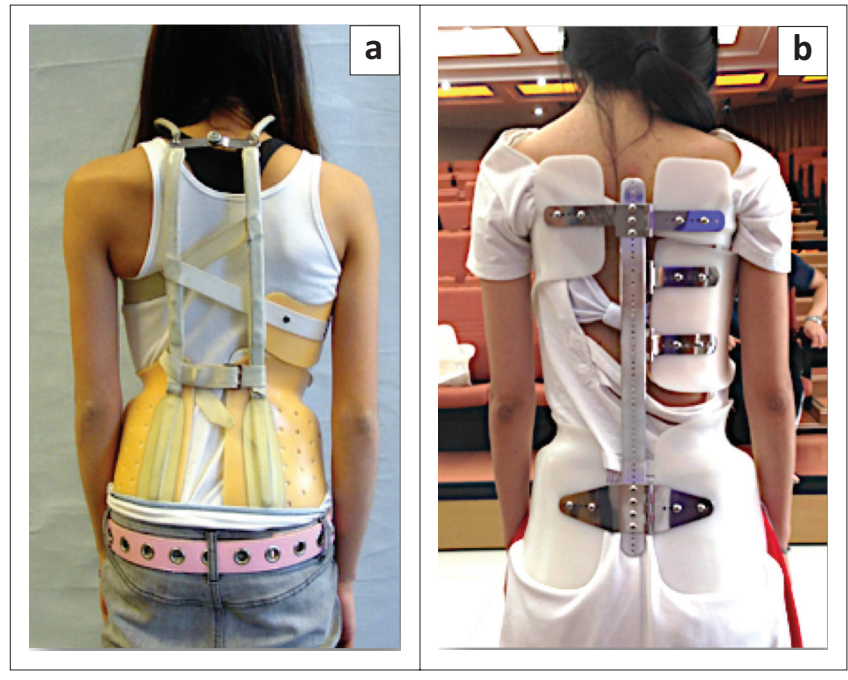

Source: Photos provided by the first author, Hans-Rudolf Weiss

FIGURE 6: (a) Scoliosis patient in a Milwaukee brace and (b) another in a Lyon brace according to Stagnara. Both braces were made for a right thoracic curve.

pressure pads. These types of braces also include the SPORT brace from Italy (Zaina et al. 2011) as well as the Osaka Medical College (OMC) brace (Kuroki et al. 2015). While the SPORT brace, unlike the Boston brace, has front closures, the OMC brace compared to the Boston brace has an axillary support with the aim of improving the corrections of the thoracic curvatures.

This list of different braces for the treatment of scoliosis does not claim to be exhaustive. There are other types of braces available with more regional references, some of which are not listed in the scientific literature or may have a limited range of indications.

In a recent review, it has been shown that braces as applied today have a wide range of results (Weiss \& Turnbull 2020b). The success rates ranged from less than $50 \%$ to more than $90 \%$. This may be attributed to devices being modelled by plaster cast. Standardisation is not possible with this method of manufacturing. Computer aided design/computer aided manufacturing (CAD/CAM) can be used to standardise brace application. However, the use of CAD/CAM technology alone will not lead to an improvement of the treatment results, but a standardised pattern specific approach addressing the individual curve patterns obviously will (Weiss et al. 2021).

Brace application may adversely impact patients as they may experience physical discomfort, psychological distress, and in some instances the brace may be painful to wear. The aim for future developments should therefore be to improve the success rate and reduce physical discomfort as well as psychological distress in patients who wear braces (Weiss et al. 2007). Besides the influence of a brace on the spinal curve, the possible cosmetic improvements may be important to the patient. The purpose of this article is to provide an overview of the state of the art of scoliosis bracing and to provide recommendations with respect to the most appropriate bracing approach. 


\section{Method}

A narrative review of the scientific literature was carried out to substantiate the statements made in this article. The search engines used were: Pub Med, Medline, Embase, Cochrane database, and Google Scholar. Our review analysed outcomes of different brace types used for the management of patients with scoliosis.

The changes in the angle of curvature measured according to $\mathrm{Cobb}$ at the end of treatment can be regarded as the most important outcome parameter (Asher \& Burton 2006; Kruzel \& Moramarco 2020). A variation in the angle of curvature within the range of + or $-5^{\circ}$ is generally viewed as unchanged. Changes of $6^{\circ}$ and more go beyond the average technical measurement error and are viewed as actual changes. An increase in the Cobb angle is considered progression and a decrease is considered an improvement. Treatment is generally considered successful if the main curvature has not deteriorated by more than $5^{\circ}$.

In addition to the changes in the Cobb angle, it is also important to assess patients with scoliosis as to whether and to what extent changes in the external appearance can be achieved through treatment with a brace. Therefore, studies were also sought in which cosmetic changes were reported.

Search terms used were: (1) scoliosis, brace treatment, rate of success and (2) scoliosis, brace application, cosmetic outcome. Studies published between 1970 and June 2021 are included.

\section{Ethical considerations}

This article followed all ethical standards for research without direct contact with human or animal participants.

\section{Results}

\section{Results of the Boston brace and other symmetric brace types}

The term TLSO describes all underarm braces and the Boston brace is one of these. Usually other TLSO used are more symmetric 'Boston like' braces. In many articles the term TLSO is not specified, and the brace used is not documented with a picture. However, usually devices called TLSO use the same principles of correction, namely 3-point pressure application and compression.

As shown in Table 1, in outcome studies the success rates vary between $60 \%$ and $81 \%$. However, the study by Hanks et al. (1988) analysed a more mature patient sample than more recent articles (Weinstein et al. 2013; Weiss et al. 2021). Therefore, this article is not comparable to more recent articles and without this article the success rates are between $60 \%$ and $75 \%$. As early onset idiopathic scoliosis has a different prognosis than AIS, therefore the articles by Harshavardhana and Lonstein (2018) and Moreau et al. (2014) cannot be considered comparable.
As early as 1995, the prospective controlled multicentre study by Nachemson and Peterson supported the treatment with a Boston brace with high quality evidence. Progression of $6^{\circ}$ or more was prevented in $70 \%$ of the patients from the treatment group.

The Bracing for Adolescent Idiopathic Scoliosis Trial (BRAIST) by Weinstein et al. (2013) utilised a randomised controlled study design and thus provides a high level of evidence. However, the criteria set for success in the study were less strict than in other studies. Treatment is normally viewed as successful if the main curve of scoliosis does not increase by $6^{\circ}$ or more. However, the success criterion of the BRAIST study was broader, indicating that if the curvature did not reach or exceed $50^{\circ}$, the treatment was deemed to be successful. Thus, there may be a certain number of patients in this study whose curvature deteriorated by $>5^{\circ}$, but who were still rated as successful as their curvature did not reach the set limit of $50^{\circ}$.

\section{Results of the Chêneau brace and other asymmetric brace types}

In studies in different populations, Chêneau-based applications may lead to better end results when compared to the results of the Boston brace (Minsk et al. 2017; Weiss \& Kleban 2015; Weiss et al. 2021). In a pilot study comparing the Rigo-Chêneau brace with the Boston brace in the same population it was found that the Rigo-Chêneau brace with respect to treatment success was superior to the Boston brace (Minsk et al. 2017). Other studies also support the hypothesis that Chêneau style braces may lead to better outcomes than Boston style braces (Weiss \& Kleban 2015; Weiss et al. 2021). However the success rates of Chêneau style braces vary to a great extent and may be even worse than the results of the Boston brace or other TLSOs (see Table 1).

The optimal planning and cast modelling of a hand crafted Chêneau brace (Weiss et al. 2000) is a complex procedure to be mastered by the orthopaedic technician. Because of the relatively low prevalence of scoliosis requiring treatment (approx. 0.5\%) in the general population (Asher \& Burton 2006; Goldberg et al. 2002; Landauer et al. 2003), the opportunity for the orthopaedic technician to gain experience in a short period of time and to constantly improve his or her own skills is limited. This may be one of the reasons why the success rates for asymmetric Chêneau derivates vary to such a great extent.

Another challenge is the varying inclusion criteria. There are prospective cohorts (Weiss \& Weiss 2005; Weiss et al. 2021; Zaborowska-Sapeta et al. 2011), retrospective chart reviews (Minsk et al. 2017; Pham et al. 2007), and articles with selective inclusion criteria varying by Cobb angle or maturity. The article by De Giorgi et al. (2013) revealed a success rate of $100 \%$. However, only patients with single curve patterns were included and the average Cobb angle was comparably low ( $27^{\circ}$ at average). 
Other articles utilised the Scoliosis Research Society (SRS) inclusion criteria for studies on bracing (Age 10-14 years, Risser 0-2, Cobb angles 25-40 ; Richards et al. 2005) and patient cohorts with average Cobb angles between $31^{\circ}$ and $33^{\circ}$ (Weiss et al. 2019, 2021; Zaborowska-Sapeta et al. 2011). Studies regarding the Chêneau brace outcomes revealed success rates between less than $50 \%$ and more than $90 \%$ (see Table 1).

While the Lyon brace is a more symmetric TLSO (De Mauroy et al. 2011), the Art brace implements a corrective movement and may be seen to act more like a Chêneau style brace rather than a symmetric TLSO of the Boston style brace (De Mauroy et al. 2014). In their retrospective study, the authors found a success rate of $95 \%$, however the patients treated with the Art brace had correcting casts prior to the application of the Art brace.

\section{Results of night-time braces}

Promising results have been found for the Charleston bending brace as well as for the Providence brace (see Table 1). In a recent article by Simony et al. (2019), a success rate of $89 \%$ was reported. The authors reported to have utilised the SRS inclusion criteria for studies on bracing (Richards et al. 2005). In the article, only patients included were with a primarily high in-brace correction $(>60 \%)$, while patients with lower in-brace corrections $(<60 \%)$ were excluded. Furthermore, in the cohort provided, the Risser stage was not reported, therefore we cannot be sure that all patients have met the SRS inclusion criteria. These challenges were addressed by Potts (2020) in his letter to the editor.

Another non-selective study (Davis et al. 2019) revealed a success rate of $57 \%$. In their retrospective cohort study, Janicki et al. (2007) found a rate of success of the Providence brace treatment of $42 \%$, whilst the success rate of their patients treated with a TLSO was even less.

As early as 1997. Rowe et al. (1997) in their meta-analysis have shown that part-time or night-time bracing is inferior to full-time use. Recent systematic reviews have come to contradictory conclusions. Whilst Ruffilli et al. (2021) in their systematic review were not able to draw a conclusion about the effectiveness of night-time bracing with the Providence brace, Costa et al. (2021) in their systematic review found that in principle there was no difference between part-time and full-time outcomes of brace management. The authors included the study by Simony et al. (2019), although this is a selective analysis of patients with high in-brace corrections. As Simony et al. (2019) did not provide patient data with in-brace corrections of $<60 \%$, their article was not eligible to be included in a systematic review on outcomes of different braces. Therefore, because of the selection bias, the conclusions from the review by Costa et al. (2021) are not justified.

\section{Results of soft braces}

Coillard et al. (2014) in their randomised controlled study found a success rate of $73.1 \%$ for their patients treated with the SpineCor in a cohort with curves between $15^{\circ}$ and $30^{\circ}$ and a Risser stage between 0 and 2 . These results were not confirmed in independent high-quality studies (Guo et al. 2014; Weiss \& Weiss 2005; Wong et al. 2008) - one study a prospective controlled design (Weiss \& Weiss 2005) and two randomised controlled designs (Guo et al. 2014; Wong et al. 2008). In all three articles, SpineCor treatment had a success rate significantly lower than that of rigid orthoses. For other soft braces, according to our review, there are no data available with SRS comparable inclusion criteria. In the study by Bulthuis et al. (2008), only patients with proven flexibility during a bending x-ray were included.

\section{Cosmetic outcomes of brace treatment}

Studies on brace application seem to focus exclusively on the Cobb angle, although this may be of minor importance for patients with AIS. In this largest group of patients with scoliosis, serious health problems are the exception, even in untreated patients (Asher \& Burton 2006; Kruzel \& Moramarco 2020; Weinstein et al. 2003; Weiss et al. 2016). Therefore, future studies should place an emphasis on which braces are able to positively influence the trunk asymmetry. One parameter for measuring trunk asymmetry is the angle of trunk rotation (ATR) (Bunnell 2005). However, this value only describes the trunk asymmetry when the trunk is bent forward. Even if this value improves only slightly, the improvement in trunk asymmetry in the upright position may be clearly visible (Figures 7 and Figure 8; Weiss et al. 2021). An improvement in trunk asymmetry can be evaluated by using reliable surface topography measurements (Rothstock et al. 2020). Future studies should place more emphasis on cosmetically important clinical parameters especially in patients with AIS because for patients living with idiopathic scoliosis the trunk deformity or their appearance are likely to be more important than the Cobb angle and also because most patients have a rather benign form of scoliosis, which does

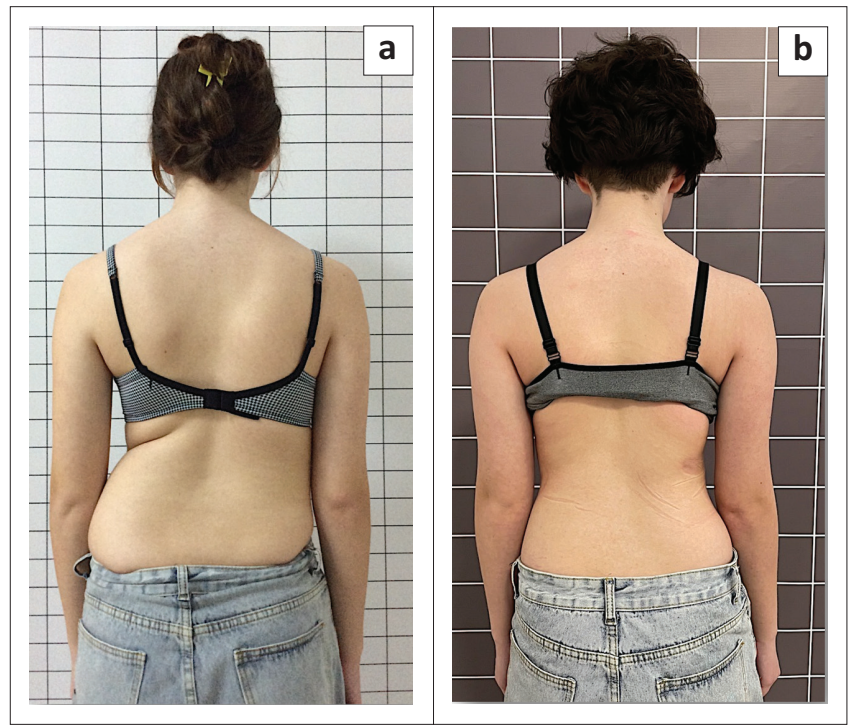

Source: Photos provided by the fourth author, Maksym Borysov

FIGURE 7: (a) Patient with a significant curve, (b) with a full clinical correction after treatment with a high impact Chêneau-style brace. 


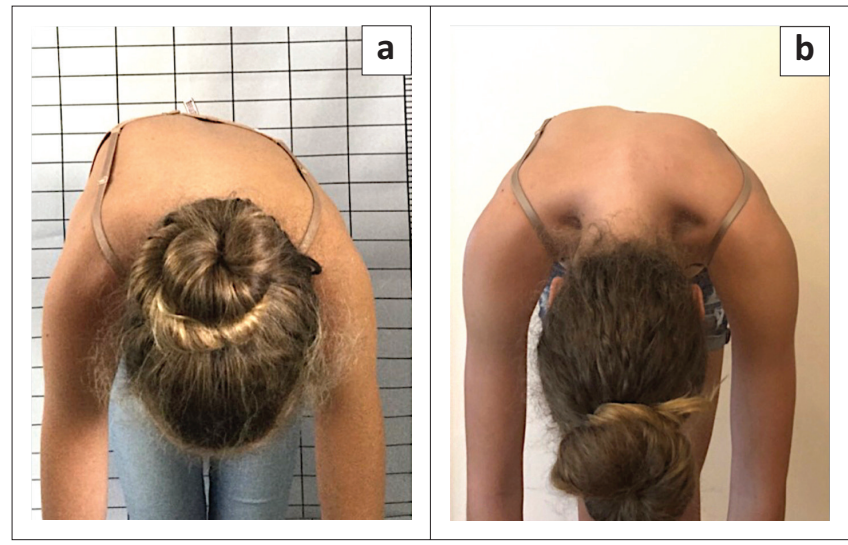

Source: Photos provided by the fourth author, Maksym Borysov

FIGURE 8: (a) Immature patient with a significant rib hump, (b) with a clear improvement of the rib hump as the intermediate result after 12 months of treatment with a Gensingen brace.

not lead to serious challenges (Asher \& Burton 2006; Kruzel \& Moramarco 2020; Weinstein et al. 2003; Weiss et al. 2016).

Obviously, there is a limited number of studies on cosmetic outcomes of brace treatment (Grivas \& Vasiliadis 2008; Negrini et al. 2012; Rigo 2003; Weiss et al. 2019; Weiss \& Moramarco 2021; Weiss et al. 2021) compared to the numerous studies which use the Cobb angle as an outcome parameter (see Table 1). Grivas and Vasiliadis (2008) in their study found that brace treatment when using a modified Boston brace improved the ATR in lumbar and thoracolumbar curves significantly, while thoracic curves did not improve. In a recent article with a cohort using the Gensingen brace (Weiss et al. 2021), the ATR improved in thoracic as well as in lumbar curves. This indicates that cosmetically important parameters can also significantly improve with high correction braces. For the patient, this may be more important than the changes in the Cobb angle, which in the end did not improve statistically significantly. An aesthetic index was used by Negrini et al. (2012) to demonstrate that brace treatment may improve the trunk deformity in patients with a scoliosis.

\section{Discussion}

Having to wear a brace only overnight or to enjoy full freedom of movement in a corrective device must be perceived by patients with scoliosis as a convincing argument for one or the other brace model. When the attending physician selects a suitable brace, however, the main focus should be on the brace application's success.

The variability of the results found for all types of braces (Table 1) shows that not one type of brace is fundamentally better than another, after all, the results vary within the individual brace families as well. When considering the best possible care for patients, an averaging of the results, as in the study by Costa et al. (2021), apparently does not support the idea of identifying the best possible treatment approach.

All articles should be read critically by the reader, as even a study utilising the best possible study design could still have shortcomings and limitations. The randomised controlled trial by Weinstein et al. (2013), for example, does not contain any information on the correction effect in the orthosis and the orthosis used is not described in detail, let alone documented in a picture.

The study by Simony et al. (2019) only included patients who achieved a correction effect of $60 \%$ and more in the brace. This information was not presented in the abstract and no information was provided in the text regarding the progression or regression of patients with lower correction effects. Nevertheless, the study was found to be eligible to be included in a systematic review with meta-analysis (Costa et al. 2021).

As shown in Figure 9, there are patients with their curves at first progressing in a night-time brace and then, after switching to a CAD Chêneau derivate, showing improvement during the management with the new brace. This shows that a progression in a less effective brace is not the end of the road for patients, and will not automatically lead to surgery. These patients, however, certainly would benefit more from brace treatment when the initial treatment was a CAD Chêneau style brace of higher quality.

For those affected, three questions arise: (1) which brace and what wearing time would provide the best chances of success, (2) which brace will have a positive effect on torso deformity, and (3) which brace is the smallest and most comfortable? A brace that allows complete freedom of movement is certainly the most comfortable for patients, but the following question arises: How can a brace achieve the corrective effects necessary in the treatment of scoliosis with complete freedom of movement?

What can be deduced from this narrative review is that the name of the brace alone does not necessarily provide information regarding the chances of success of the treatment. However, Table 1 shows that the best results are achieved from braces that produce a corrective movement. These braces are asymmetrical and there are corresponding free spaces in relation to the pressure zones, which make the corrective movement possible. However, these restorations must correspond to the individual curvature pattern as accurately as possible.

Treating different curvature patterns with different corrective movements in the brace and also in three dimensions is a very complex matter with numerous potential mistakes. Therefore, applying an asymmetrical brace, which provides reliable and good quality results according to the curvature pattern of the patient, using standardised algorithms is recommended. This complex fitting can be best managed, with the assistance of computer technology. Such CAD/CAM brace series have been available for 20 years and are constantly being developed further. 

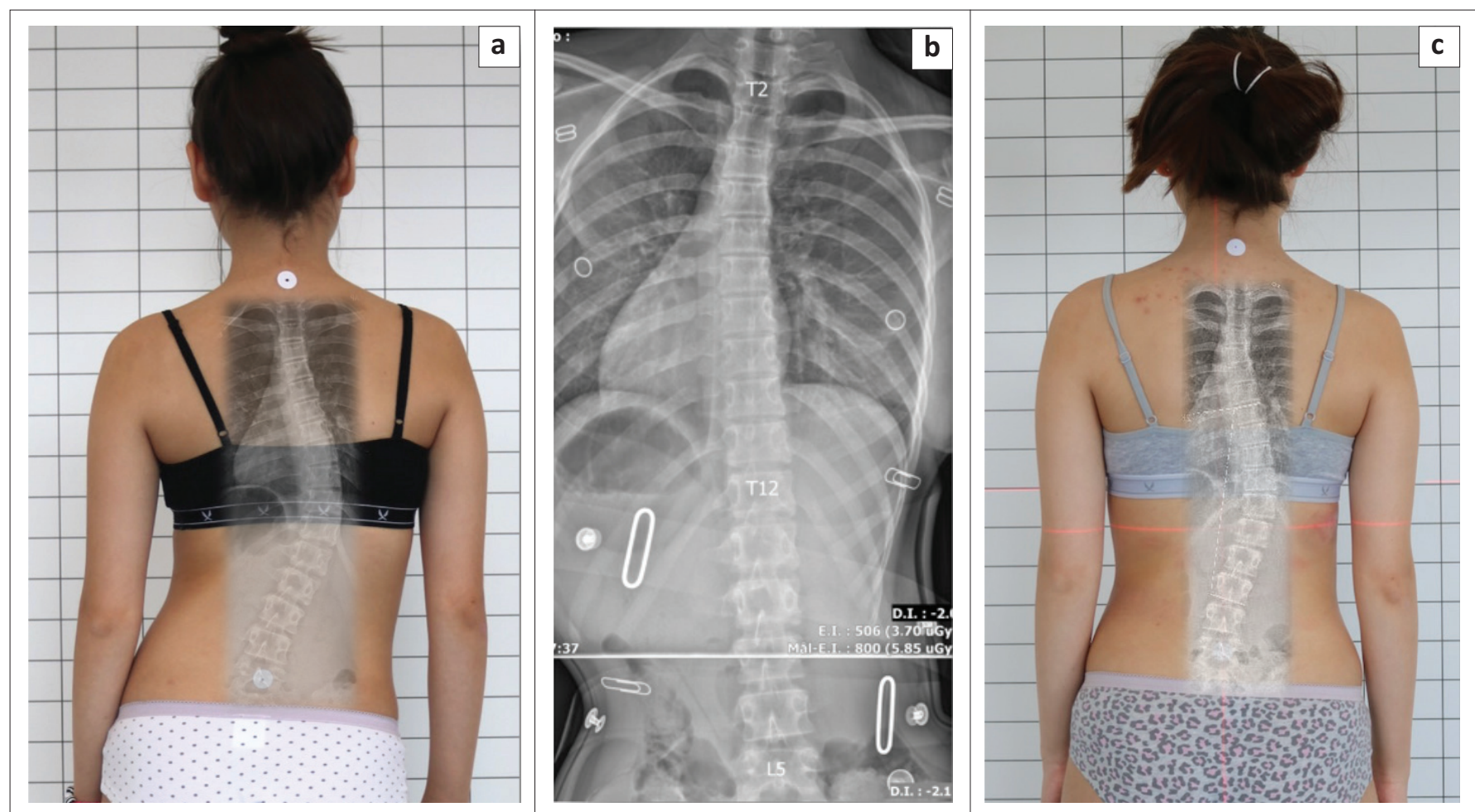

Source: All photos in this figure are with kind permission from Dansk Skoliose Center, Copenhagen

FIGURE 9: (a) This patient at first was treated with a Providence brace and progressed from $31^{\circ}$ to $41^{\circ}$ within 6 months before switching to a computer aided design Chêneau brace. (b) In the Chêneau brace, the $41^{\circ}$ curve was fully corrected. (c) After 8 months, the compliant patient reduced the curve to $29^{\circ}$ and showed improved trunk asymmetry.

In the case of night-time braces, the correction effects are determined with an X-ray examination in the supine position. Therefore, the percentage correction effects in the brace differ significantly from the correction effects in a full-time brace, which are determined while standing. The correction results while standing are usually lower because gravity loads the curvatures in the upright position and relieves them in the supine position. With full time braces of higher quality, correction effects of approximately $50 \%$ can be achieved on average, which according to Landauer et al. (2003) promises a final correction if the patient is compliant.

Previously, it was hypothesised that the initially achieved correction in brace applications of patients with scoliosis would regress within 2 years post-treatment (Landauer et al. 2003). Currently when using high-correcting braces, a significant decrease of initial results in the long-term is no longer expected. Aulisa et al. (2017) observed permanent corrections more than 10 years after weaning the patient from the brace, and the follow-up results did not differ significantly from the results achieved immediately after weaning.

The corrective effect in the brace generally decreases with increasing maturity (Aulisa et al. 2019). Since the results of brace application in patients with scoliosis is clearly dependent on the in-brace correction and the brace wearing time (compliance) (Landauer et al. 2003; Rivett, Stewart \& Potterton 2014; Van den Bogaart et al. 2019; Xu et al. 2017), the end results with high-quality braces seem to be the best in immature patients, as their curvatures can be corrected more easily.
Studies with patients having larger angles of curvature $\left(>40^{\circ}\right)$ show that high success rates can also be achieved with high-quality braces (Aulisa et al. 2019; Weiss et al. $2017 b, 2021)$. These results indicate the need for a standardisation of brace applications for patients with scoliosis to ensure that the impairment in the quality of life of the patient while wearing the brace is a worthwhile endeavour for the patient (Weiss et al. 2007).

To avoid over- or undertreatment (wait and see), it should be mandatory for the informing professional to disclose commonly accepted guidelines where patients can easily find their individual prognosis (Weiss \& Turnbull 2020a). This would decrease the uncertainty of patients when receiving contradictory advice and could possibly increase the compliance of patients.

\section{Limitations of this article}

This state-of-the-art article gives an overview of the most important types of braces that are used to treat patients with scoliosis. It does not claim to be complete. It is based on the literature of the common databases without the rigour of a systematic review.

\section{Conclusion}

Taking into account that brace application may impact the patient with possible physical discomfort and psychological distress: good quality management in brace application for patients with scoliosis is needed to ensure the best possible 
outcome and least stressful treatment. The wide variation of success rates as found in the literature (see Table 1) does not seem acceptable for patients when considering how they sacrifice their time and quality of life to wear the brace, sometimes for years. Curve progression that occurs during the pubertal growth spurt in an ineffective brace cannot easily be reversed at a later stage.

\section{Acknowledgements}

The authors would like to thank Dr. Matthew Potts for copyediting the first version of this article.

\section{Competing interests}

H.R.W., currently serves as the senior consultant for Koob Scolitech $\mathrm{GmbH}$. The company is held by the spouse of the author. He has held a patent on a sagittal realignment brace (EP 1604624 A1). The co-authors declare that they have no financial or personal relationships that may have inappropriately influenced them in writing this article.

\section{Authors' contributions}

H.R.W. contributed to the conception, literature review (Pub Med), first draft and project administration. T.K.C. contributed to the manuscript preparation, review of databases other than Pub Med and the data analysis. M.L. contributed to the data analysis, patient pictures and advice with regards to orthotics. M.B. contributed to the manuscript preparation, patient pictures and review.

\section{Funding information}

This research received no specific grant from any funding agency in the public, commercial or not-for-profit sectors.

\section{Data availability}

Data sharing is not applicable to this article, as no new data were created or analysed in this study.

\section{Disclaimer}

The views and opinions expressed in this article are those of the authors and do not necessarily reflect the official policy or position of any affiliated agency of the authors

\section{References}

Asher, M.A. \& Burton, D.C., 2006, 'Adolescent idiopathic scoliosis: Natural history and long term treatment effects', Scoliosis 1(1), 2. https://doi.org/10.1186/17487161-1-2

Aulisa, A.G., Guzzanti, V., Falciglia, F., Galli, M., Pizzetti, P. \& Aulisa, L., 2017, 'Curve progression after long-term brace treatment in adolescent idiopathic scoliosis: Comparative results between over and under 30 Cobb degrees - SOSORT 2017 award winner', Scoliosis and Spinal Disorders 12, 36. https://doi.org/10.1186/ s13013-017-0142-y

Aulisa, A.G., Guzzanti, V., Falciglia, F., Giordano, M., Galli, M. \& Aulisa, L., 2019, 'Brace treatment of Idiopathic Scoliosis is effective for a curve over 40 degrees, but is the evaluation of Cobb angle the only parameter for the indication of treatment?', European Journal of Physical and Rehabilitation Medicine 55(2), 231-240.

Babaee, T., Kamyab, M., Ganjavian, M.S., Rouhani, N. \& Jarvis, J., 2020, 'Success rate of brace treatment for juvenile-onset idiopathic scoliosis up to skeletal maturity', International Journal of Spine Surgery 14(5), 824-831. https://doi.org/10.14444/7117
Blount, W.P., 1965, 'Non-operative treatment of scoliosis with the Milwaukee brace', Manitoba Medical Review 45(8), 478-480.

Bullmann, V., Halm, H.F., Lerner, T., Lepsien, U., Hackenberg, L. \& Liljenqvist, U., 2004, 'Prospektive Untersuchung zur Korsettbehandlung bei idiopathischen Skoliosen [Prospective evaluation of braces as treatment in idiopathic scoliosis]', Zeitschrift fur Orthopadie und ihre Grenzgebiete 142(4), 403-409.

Bulthuis, G.J., Veldhuizen, A.G. \& Nijenbanning, G., 2008, 'Clinical effect of continuous corrective force delivery in the non-operative treatment of idiopathic scoliosis: A prospective cohort study of the TriaC-brace', European Spine Journal 17(2), 231-239. https://doi.org/10.1007/s00586-007-0513-9

Bunnell, W.P., 2005, 'Selective screening for scoliosis', Clinical Orthopaedics and Related Research 434, 40-45. https://doi.org/10.1097/01.blo.0000163242. 92733.66

Cheung, J.P.Y., Cheung, P.W.H., Yeng, W.C. \& Chan, L.C.K., 2020, 'Does curve regression occur during underarm bracing in patients with adolescent idiopathic scoliosis?', Clinical Orthopaedics and Related Research 478(2), 334-345. https://doi. org/10.1097/CORR.0000000000000989

Chik, S.K.T., 2020, 'Classification and terminology', in M. Moramarco, M. Borysov, S.Y. Ng \& H.R. Weiss (eds.), Schroth's textbook of scoliosis and other spinal deformities, pp. 150-158, Cambridge Scholars Publishing, Newcastle upon Tyne.

Coillard, C., Circo, A.B. \& Rivard, C.H., 2014, 'A prospective randomized controlled trial of the natural history of idiopathic scoliosis versus treatment with the SpineCor brace', Sosort Award 2011 winner', European Journal of Physical and Rehabilitation Medicine 50(5), 479-487.

Costa, L., Schlosser T.P.C., Jimale, H., Homans, J.F., Kruyt, M.C. \& Castelein, R.M. 2021 'The effectiveness of different concepts of bracing in Adolescent Idiopathic Scoliosis (AIS): A systematic review and meta-analysis', Journal of Clinical Medicine 10(10), 2145. https://doi.org/10.3390/jcm10102145

D’Amato, C.R., Griggs, S. \& McCoy, B., 2001, 'Nighttime bracing with the Providence brace in adolescent girls with idiopathic scoliosis', Spine 26(18), 2006-2012. https://doi.org/10.1097/00007632-200109150-00014

Davis, L., Murphy, J.S., Shaw, K.A., Cash, K., Devito, D.P. \& Schmitz, M.L., 2019, 'Nighttime bracing with the Providence thoracolumbosacral orthosis for treatment of adolescent idiopathic scoliosis: A retrospective consecutive clinical treatment of adolescent idiopathic scoliosis: A retrospective consecutive clinical
series', Prosthetics and Orthotics International 43(2), 158-162. https://doi. series', Prosthetics and Orthotics
org/10.1177/0309364618792727

De Giorgi, S., Piazzolla, A., Tafuri, S., Borracci, C., Martucci, A. \& De Giorgi, G., 2013 'Chêneau brace for adolescent idiopathic scoliosis: Long-term results. Can it prevent surgery?', European Spine Journal 22 (Suppl 6), S815-S822. https://doi. prevent surgery?', European Spine
org/10.1007/s00586-013-3020-1

De Mauroy, J.C., Lecante, C. \& Barral, F., 2011, “"Brace Technology” thematic series The Lyon approach to the conservative treatment of scoliosis', Scoliosis 6,4 The Lyon approach to the conservative
https://doi.org/10.1186/1748-7161-6-4

De Mauroy, J.C., Lecante, C., Barral, F. \& Pourret, S., 2014, 'Prospective study and new concepts based on scoliosis detorsion of the first 225 early in-brace radiological results with the new Lyon brace: ARTbrace', Scoliosis 9, 19. https://doi. results with the new Lyon
org/10.1186/1748-7161-9-19

Goldberg, C.J., Moore, D.P., Fogarty, E.E. \& Dowling, F.E., 2002, 'Adolescent idiopathic scoliosis: Natural history and prognosis', Studies in Health Technology and Informatics 91, 59-63.

Grivas, T.B. \& Vasiliadis, E.S., 2008, 'Cosmetic outcome after conservative treatment of idiopathic scoliosis with a dynamic derotation brace', Studies in Health Technology and Informatics 135, 387-392.

Guo, J., Lam, T.P., Wong, M.S., Ng, B.K., Lee, K.M., Liu, K.L. et al., 2014, 'A prospective randomized controlled study on the treatment outcome of SpineCor brace versus rigid brace for adolescent idiopathic scoliosis with follow-up according to the SRS standardized criteria', European Spine Journal 23(12), 2650-2657. https://doi. standardized criteria', European
org/10.1007/s00586-013-3146-1

Hanks, G.A., Zimmer, B. \& Nogi, J., 1988, 'TLSO treatment of idiopathic scoliosis. An analysis of the Wilmington jacket', Spine 13(6), 626-629. https://doi. org/10.1097/00007632-198806000-00005

Harshavardhana, N.S. \& Lonstein, J.E., 2018, 'Results of bracing for juvenile idiopathic scoliosis', Spine Deformity 6(3), 201-206. https://doi.org/10.1016/j.jspd.2017. 10.009

Hopf, C. \& Heine, J., 1985, 'Langzeitergebnisse der konservativen Behandlung der Skoliose mit dem Chêneau-Korsett [Long-term results of the conservative treatment of scoliosis using the Chêneau brace]', Zeitschrift fur Orthopadie und treatment of scoliosis using the Chêneau brace]', Zeitschrift fur Orthopadie und
ihre Grenzgebiete 123(3), 312-322. https://doi.org/10.1055/s-2008-1045157

Janicki, J.A., Poe-Kochert, C., Armstrong, D.G. \& Thompson, G.H., 2007, 'A comparison of the thoracolumbosacral orthoses and providence orthosis in the
treatment of adolescent idiopathic scoliosis: Results using the new SRS inclusion treatment of adolescent idiopathic scoliosis: Results using the new SRS inclusion 27(4), 369-374. https://doi.org/10.1097/01.bpb.0000271331.71857.9a

Kruzel, K., Moramarco, M., 2020, 'Idiopathic scoliosis', in M. Moramarco, M. Borysov, S.Y. Ng \& H.R. Weiss (eds.), Schroth's textbook of scoliosis and other spinal deformities, pp. 380-400, Cambridge Scholars Publishing, Newcastle upon Tyne.

Kuroki, H., Inomata, N., Hamanaka, H., Higa, K., Chosa, E. \& Tajima, N., 2015, 'Efficacy of the Osaka Medical College (OMC) brace in the treatment of adolescent idiopathic scoliosis following Scoliosis Research Society brace studies criteria', Scoliosis 10, 12. https://doi.org/10.1186/s13013-015-0036-9

Landauer, F., Wimmer, C. \& Behensky, H., 2003, 'Estimating the final outcome of brace treatment for idiopathic thoracic scoliosis at 6-month follow-up', Pediatric Rehabilitation 6(3-4), 201-207. https://doi.org/10.1080/136384903 10001636817 
Lee, C.S., Hwang, C.J., Kim, D.J., Kim, J.H., Kim, Y.T., Lee, M.Y., et al., 2012, ‘Effectiveness of the Charleston night-time bending brace in the treatment of adolescent of the Charleston night-time bending brace in the treatment of adolescent
idiopathic scoliosis', Journal of Pediatric Orthopedics 32(4), 368-372. https://doi. idiopathic scoliosis', Journal of Pediatric

Lonstein, J.E. \& Carlson, J.M., 1984, 'The prediction of curve progression in untreated idiopathic scoliosis during growth', The Journal of Bone and Joint Surgery 66(7), 1061-1071. https://doi.org/10.2106/00004623-19846607000013

Minsk, M.K., Venuti, K.D., Daumit, G.L. \& Sponseller, P.D., 2017, 'Effectiveness of the Rigo Chêneau versus Boston-style orthoses for adolescent idiopathic scoliosis: A retrospective study', Scoliosis and Spinal Disorders 12, 7. https://doi.org/10.1186/ s13013-017-0117-z

Moreau, S., Lonjon, G., Mazda, K. \& Ilharreborde, B., 2014, 'Detorsion night-time bracing for the treatment of early onset idiopathic scoliosis', Orthopaedics \& Traumatology, Surgery \& Research 100(8), 935-939. https://doi.org/10.1016/j. otsr.2014.05.024

Nachemson, A.L. \& Peterson, L.E., 1995, 'Effectiveness of treatment with a brace in girls who have adolescent idiopathic scoliosis. A prospective, controlled study based on data from the Brace Study of the Scoliosis Research Society', The Journal of Bone and Joint Surgery 77(6), 815-822. https://doi.org/10.2106/00004623199506000-00001

Negrini, S., Donzelli, S., Lusini, M. \& Zaina, F., 2012, 'Bracing can reduce high degree curves and improve aesthetics immediately after the end of growth', Final results of a retrospective case series', Studies in Health Technology and Informatics 176 393-396.

Pham, V.M., Herbaux, B., Schill, A. \& Thevenon, A., 2007, 'Evaluation du résultat du corset de Chêneau dans la scoliose idiopathique de l'adolescent [Evaluation of the Chêneau brace in adolescent idiopathic scoliosis]', Annales de readaptation et de medecine physique: revue scientifique de la Societe francaise de reeducation fonctionnelle de readaptation et de medecine physique 50(3), 125-133. https:// doi.org/10.1016/j.annrmp.2006.11.003

Potts, M.A., 2020, 'Letter to the editor concerning "Providence nighttime bracing is effective in treatment for adolescent idiopathic scoliosis even in curves large than 35" by A. Simony, I. Beuschau, L. Quisth et al. (Eur Spine J; [2019]: doi:10.1007/s00586-019-06077-z)', European Spine Journal 29(3), 641-642. https://doi.org/10.1007/s00586-019-06266-w

Price, C.T., Scott, D.S., Reed, F.E. Jr. \& Riddick, M.F., 1990, 'Nighttime bracing for adolescent idiopathic scoliosis with the Charleston bending brace. Preliminary report', Spine 15(12), 1294-1299. https://doi.org/10.1097/00007632-19901200000011

Richards, B.S., Bernstein, R.M., D'Amato, C.R. \& Thompson, G.H., 2005, 'Standardization of criteria for adolescent idiopathic scoliosis brace studies: SRS committee on bracing and nonoperative management', Spine 30(18), 2068-2077. https://do org/10.1097/01.brs.0000178819.90239.d0

Rigo, M., 2003, 'Radiological and cosmetic improvement 2 years after brace weaning A case report', Pediatric Rehabilitation 6(3-4), 195-199. https://doi.org/10.1080/ 13638490310001636826

Rivett, L., Stewart, A. \& Potterton, J., 2014, 'The effect of compliance to a Rigo System Cheneau brace and a specific exercise programme on idiopathic scoliosis curvature: A comparative study: SOSORT 2014 award winner', Scoliosis 9, 5. https://doi.org/10.1186/1748-7161-9-5

Rothstock, S., Weiss, H.R., Krueger, D. \& Paul, L., 2020, 'Clinical classification of scoliosis patients using machine learning and markerless 3D surface trunk data', Medical \& Biological Engineering \& Computing 58(12), 2953-2962. https://doi. org/10.1007/s11517-020-02258-x

Rowe, D.E., Bernstein, S.M., Riddick, M.F., Adler, F., Emans, J.B. \& Gardner-Bonneau D., 1997, 'A meta-analysis of the efficacy of non-operative treatments for idiopathic scoliosis', The Journal of Bone and Joint Surgery 79(5), 664-674. https:// doi.org/10.2106/00004623-199705000-00005

Ruffilli, A., Fiore, M., Barile, F., Pasini, S. \& Faldini, C., 2021, 'Evaluation of night-time bracing efficacy in the treatment of adolescent idiopathic scoliosis: A systematic review', Spine Deformity 9(3), 671-678. https://doi.org/10.1007/s43390-020review',

Seifert, J. \& Selle, A., 2009, 'Hat die Nachtorthese in der Skoliosetherapie noch eine Berechtigung? [Is night-time bracing still appropriate in the treatment of
idiopathic scoliosis?]', Der Orthopade 38(2), 146-150. https://doi.org/10.1007/ s00132-008-1381-7

Simony, A., Beuschau, I., Quisth, L., Jespersen, S.M., Carreon, L.Y. \& Andersen, M.O., 2019, 'Providence nighttime bracing is effective in treatment for adolescent idiopathic scoliosis even in curves larger than $35^{\prime}$, European Spine Journal 28(9), 2020-2024. https://doi.org/10.1007/s00586-019-06077-z

Thompson, R.M., Hubbard, E.W., Jo, C.H., Virostek, D. \& Karol, L.A., 2017, 'Brace success is related to curve type in patients with adolescent idiopathic scoliosis', The Journa of Bone and Joint Surgery 99(11), 923-928. https://doi.org/10.2106/JBJS.16.01050

Van den Bogaart, M., Van Royen, B.J., Haanstra, T.M., De Kleuver, M. \& Faraj, S., 2019 'Predictive factors for brace treatment outcome in adolescent idiopathic scoliosis: A best-evidence synthesis', European Spine Journal 28(3), 511-525. https://doi. org/10.1007/s00586-018-05870-6

Watts, H.G., Hall, J.E. \& Stanish, W., 1977, 'The Boston brace system for the treatment of low thoracic and lumbar scoliosis by the use of a girdle without superstructure' Clinical Orthopaedics and Related Research 126, 87-92. https://doi.org/10. 1097/00003086-197707000-00012
Weinstein, S.L., Dolan, L.A., Spratt, K.F., Peterson, K.K., Spoonamore, M.J. \& Ponseti, I.V., 2003, 'Health and function of patients with untreated idiopathic scoliosis: A 50-year natural history study', JAMA 289(5), 559-567. https://doi.org/10.1001/ jama.289.5.559

Weinstein, S.L., Dolan, L.A., Wright, J.G. \& Dobbs, M.B., 2013, 'Effects of bracing in adolescents with idiopathic scoliosis', The New England Journal of Medicine 369(16), 1512-1521. https://doi.org/10.1056/NEJMoa1307337

Weiss, H.R., 2010, 'Brace technology thematic series - The Gensingen brace ${ }^{\mathrm{TM}}$ in the treatment of scoliosis', Scoliosis 5, 22. https://doi.org/10.1186/1748-7161-5-22

Weiss, H.R., 2021, 'A critical appraisal on soft brace treatment in patients with scoliosis', Highlights on Medicine and Medical Research 11, 138-145. https://doi. org $/ 10.9734 / \mathrm{bpi} / \mathrm{hmmr} / \mathrm{v} 11 / 8653 \mathrm{D}$

Weiss, H.R., Karavidas, N., Moramarco, M. \& Moramarco, K., 2016, 'Long-term effects of untreated adolescent idiopathic scoliosis: A review of the literature', Asian Spine Journal 10(6), 1163-1169. https://doi.org/10.4184/asj.2016.10. 6.1163

Weiss, H.R. \& Kleban, A., 2015, 'Development of CAD/CAM based brace models for the treatment of patients with scoliosis-classification based approach versus finite element modelling', Asian Spine Journal 9(5), 661-667. https://doi.org/10.4184/ asj.2015.9.5.661

Weiss, H.R., Lay, M., Seibel, S. \& Kleban, A., 2021, 'Ist eine Verbesserung der Behandlungssicherheit in der Korsettversorgung von Skoliosepatienten durch Anwendung standardisierter CAD-Algorithmen möglich? [Is it possible to improve treatment safety in the brace treatment of scoliosis patients by using standardized CAD algorithms?]', Der Orthopade 50(6), 435-445. https://doi.org/10.1007/ s00132-020-04000-9

Weiss, H.R. \& Moramarco, M., 2021, 'Remodeling of trunk and backshape deformities in patients with scoliosis using standardized asymmetric CAD/CAM braces' Highlights on Medicine and Medical Research 11, 104-114. https://doi.org/ 10.9734/bpi/hmmr/v11/8647D

Weiss, H.R., Negrini, S., Rigo, M., Kotwicki, T., Hawes, M.C., Grivas, T.B. et al., 2006 'Indications for conservative management of scoliosis (guidelines)', Scoliosis 1, 5 . https://doi.org/10.1186/1748-7161-1-5

Weiss, H.R., Rigo, M. \& Chêneau, J., 2000, Praxis der Chêneau-Korsettversorgung in der Skoliosetherapie, Georg Thieme Verlag, Stuttgart.

Weiss, H.R., Tournavitis, N., Nan, X., Borysov, M. \& Paul, L, 2017a, 'Workflow of CAD / CAM scoliosis brace adjustment in preparation using 3D printing', The Open Medical Informatics Journal 11, 44-51. https://doi.org/10.2174/1874431 101711010044

Weiss, H.R., Tournavitis, N., Seibel, S. \& Kleban, A., 2017b, 'A prospective cohort study of AIS patients with $40^{\circ}$ and more treated with a gensingen brace (GBW): Preliminary results', The Open Orthopaedics Journal 11(Suppl-9, M8), 1558-1567. https://doi.org/10.2174/1874325001711011558

Weiss, H.R. \& Turnbull, D., 2020a, 'Best practice recommendations for the conservative treatment of patients with spinal deformities', in M. Moramarco, M. Borysov, S.Y. Ng \& H.R. Weiss (eds.), Schroth's textbook of scoliosis and other spinal deformities, pp. 760-775, Cambridge Scholars Publishing, Newcastle upon Tyne.

Weiss, H.R. \& Turnbull, D., 2020b, 'Brace treatment for children and adolescents with scoliosis', In. Bettany-Saltikov, J and Kandasamy,G., Spinal Deformities in Adolescents, Adults and Older Adults, IntechOpen. https://doi.org/10.5772/ intechopen.91234

Weiss, H.R., Turnbull, D., Seibel, S. \& Kleban, A., 2019, 'First end-result of a prospective cohort with AIS treated with a CAD Chêneau style brace', Journal of Physical Therapy Science 31(12), 983-991. https://doi.org/10.1589/jpts.31.983

Weiss, H.R. \& Weiss, G.M., 2005, 'Brace treatment during pubertal growth spurt in girls with idiopathic scoliosis (IS): A prospective trial comparing two different concepts', Pediatric Rehabilitation 8(3), 199-206. https://doi.org/10.1080/ concepts', Pediatric

Weiss, H.R., Werkmann, M. \& Stephan, C., 2007, 'Brace related stress in scoliosis patients - Comparison of different concepts of bracing', Scoliosis 2, 10. https:// doi.org/10.1186/1748-7161-2-10

Wong, M.S., Cheng, J.C., Lam, T.P., Ng, B.K., Sin, S.W., Lee-Shum, S.L. et al., 2008, 'The effect of rigid versus flexible spinal orthosis on the clinical efficacy and acceptance of the patients with adolescent idiopathic scoliosis', Spine 33(12), 1360-1365. https://doi.org/10.1097/BRS.0b013e31817329d9

Xu, L., Qin, X., Qiu, Y. \& Zhu, Z., 2017, 'Initial correction rate can be predictive of the outcome of brace treatment in patients with adolescent idiopathic scoliosis', Clinical Spine Surgery 30(4), E475-E479. https://doi.org/10.1097/BSD.000 0000000000343

Yamane, K., Takigawa, T., Tanaka, M., Sugimoto, Y., Arataki, S. \& Ozaki, T., 2016, 'Impact of rotation correction after brace treatment on prognosis in adolescent idiopathic scoliosis', Asian Spine Journal 10(5), 893-900. https://doi.org/10.4184/ asj.2016.10.5.893

Zaborowska-Sapeta, K., Kowalski, I.M., Kotwicki, T., Protasiewicz-Fałdowska, H. \& Kiebzak, W., 2011, 'Effectiveness of Chêneau brace treatment for idiopathic scoliosis: Prospective study in 79 patients followed to skeletal maturity', Scoliosis 6(1), 2. https://doi.org/10.1186/1748-7161-6-2

Zaina, F., Fusco, C., Atanasio, S. \& Negrini, S., 2011, 'The SPoRT concept of bracing for idiopathic scoliosis', Physiotherapy Theory and Practice 27(1), 54-60. https://doi. org/10.3109/09593985.2010.503988 